\title{
Extraction and analysis of chemical constituents from mangosteen pericarp
}

\author{
Hua Liu ${ }^{1,2}$, Rong $\mathrm{He}^{1}$, Liwen Zheng ${ }^{1}$ and Shuyao Xie ${ }^{1}$ \\ ${ }^{1}$ Guangzhou College of Technology and Business, 510850 Guangzhou, China \\ ${ }^{2}$ University Putra Malaysia, 43400 Serdang, Selangor, Malaysia
}

\begin{abstract}
In order to improve the utilization efficiency of mangosteen pericarp and make rational use of its active components, the antibacterial, anti-inflammatory and anti-tumor active components, molecular formula, structural formula, physical and chemical properties and action mechanism of mangosteen pericarp were analyzed The results showed that the active components of mangosteen shell also had antioxidant activity, anti-ultraviolet radiation effect, cardiovascular disease improvement effect, neuroprotective effect and intestinal disease protection effect. Among the extraction methods of active components from mangosteen shell, supercritical fluid extraction and vegetable oil assisted extraction have the characteristics of green nature, environmental protection and energy saving, and have broad market prospects in the development and utilization of mangosteen pericarp.
\end{abstract}

\section{Introducion}

Garcinia mangostana, also known as Dendrocalamus, Dendrocalamus, mangji persimmon and daonianzi, the fruit of Garcinia mangostana, an evergreen tree of Garcinia family. It is widely planted in tropical areas. It is a kind of fruit with the same origin of medicine and food, and is known as " Fruit queen" in tropical areas. The edible part of mangosteen is only $29 \%-45 \%$, and its peel is purple brown. The pericarp of mangosteen is widely used as a traditional medicine in some countries for the treatment of abdominal pain, dysentery, infectious trauma, anti-tumor, anti-inflammatory and septic diseases. In recent years, more and more attention has been paid to the extraction of bioactive components from mangosteen peel. Mangosteen peel can extract a variety of flavonoids, with strong antioxidant capacity, free radical scavenging capacity and a variety of pharmacological activities, which are widely used in food industry, clinical and cosmetics industry. In this paper, the active components, molecular formula, structural formula, physicochemical properties and action mechanism of antibacterial, antiinflammatory, anti-tumor and anti-oxidation activities of mangosteen pericarp were analyzed, and the solvent use, extraction conditions, extraction effect and extraction components of supercritical fluid extraction, water extraction, organic solvent extraction and vegetable oil assisted extraction were studied. In order to improve the utilization efficiency of mangosteen pericarp and make rational use of its active ingredients.

\section{Chemical constituents and bioactivity of mangosteen pericarp}

\subsection{Antibacterial and anti-inflammatory effects}

The extract of mangosteen peel has strong inhibitory effect on Propionibacterium acnes and Staphylococcus epidermidis. In the study, $\alpha$-mangostin was found that $\mathrm{e}$ could not only promote the expression of autolytic genes, but also inhibit the self-protection behavior of bacteria[1]. However, the expression of CIDA and lrgb were inhibited. The pigment from mangosteen pericarp has good stability and antibacterial activity. The results showed that the extract of mangosteen pericarp had strong antibacterial effect on mold, bacteria and yeast, and the inhibitory effect increased with the increase of pigment concentration. The order of bacteriostatic effect was gambogia $>$ octococcus $>$ Bacillus subtilis $>$ Saccharomyces cerevisiae $>$ Rhizopus $>$ dysentery $>$ Escherichia coli [2]. Ye Huochun [3] found that the chloroform extract of mangosteen had significant inhibitory effect on the mycelial growth of four plant pathogenic fungi, such as Colletotrichum gloeosporioides, Rhizoctonia solani, Botrytis cinerea and mango stalk rot, and the activity varied significantly with different extraction solvents. In general, the petroleum ether extract of mangosteen peel mainly showed insecticidal activity, while the chloroform extract showed obvious antibacterial activity.

$\gamma$ - mangostin $(\gamma$ - MS $)$ is an important bioactive substance in mangosteen. Through research the potential of $\gamma$-MS to target pro-inflammatory cytokines and miRs in the progression of osteoarthritis (OA) was found $\gamma$-MS can

\footnotetext{
*Corresponding author: annylh2008@126.com
} 
inhibit inflammatory cytokines (IL-6, TNF)- $\alpha$, INF- $\gamma$ ) And factor NF- $\kappa$ B. Stat 3 and COX-2 regulate or participate in the process of cartilage destruction[4]. It was confirmed by hematoxylin eosin (H \& E) staining $\gamma$ - OA joint tissue sections of MS treatment group and non treatment group $\gamma$ - MS improved the signs of injury, maintained the structural integrity of articular cartilage (epiphysis, discoid joint and bone marrow), and reduced the inflammatory reaction.

Table1. antibacterial and anti-inflammatory active components in the pericarp of mangosteen

\begin{tabular}{|c|c|c|c|c|}
\hline $\begin{array}{c}\text { Active } \\
\text { ingredient }\end{array}$ & $\begin{array}{c}\text { Molecular } \\
\text { formula }\end{array}$ & Chemical structure formula & $\begin{array}{l}\text { Physical and } \\
\text { chemical } \\
\text { properties }\end{array}$ & Mechanism of action \\
\hline Mangostanin & $\mathrm{C}_{38} \mathrm{H}_{50} \mathrm{O}_{6}$ & & soild & $\begin{array}{l}\text { The action on Propionibacterium acnes } \\
\text { cell membrane induced autolysis of } \mathrm{P} \text {. } \\
\text { acnes, resulting in the rupture of } \\
\text { bacterial plasma membrane and the } \\
\text { release of intracellular substances, } \\
\text { leading to the death of bacteria. }\end{array}$ \\
\hline$\alpha$-mangostin & $\mathrm{C}_{24} \mathrm{H}_{26} \mathrm{O}_{6}$ & & $\begin{array}{l}\text { nsoluble in water, } \\
\text { soluble in hexane, } \\
\text { chloroform, ethyl } \\
\text { acetate and other } \\
\text { low polar solvents. }\end{array}$ & $\begin{array}{l}\text { The expression levels of CIDA and lrgb } \\
\text { were inhibited. It can reduce the content } \\
\text { of macrophages, change the polarization } \\
\text { of pro-inflammatory macrophages and } \\
\text { reduce the concentration of pro- } \\
\text { inflammatory cytokines and } \\
\text { chemotherapeutic factors. }\end{array}$ \\
\hline$\gamma$ - mangostin & $\mathrm{C}_{23} \mathrm{H}_{24} \mathrm{O}_{6}$ & & $\begin{array}{l}\text { Soluble in } \\
\text { methanol, ethanol, } \\
\text { DMSO and other } \\
\text { organic solvents. }\end{array}$ & $\begin{array}{l}\text { Inhibition of inflammatory cytokines } \\
\text { (IL- } 6, \text { TNF- } \alpha \text { 、 INF- } \gamma \text { ) and factor NF- } \\
\kappa \text { B. Stat } 3 \text { and COX-2 regulate or } \\
\text { participate in the process of cartilage } \\
\text { destruction. }\end{array}$ \\
\hline
\end{tabular}

\subsection{Antitumor activity}

Mangiferin, an extract from mangosteen peel, was first found in Tripterygium Wilfordii and proved to be toxic to four types of tumor cells: MCF-7 (human breast cancer), $\mathrm{KB}$ (human oral cancer), he La (human cervical cancer) and HT-29 (human colon cancer). Through the analysis of the anti-tumor activity of mangiferin, it was found that mangiferin had a good effect in inhibiting the proliferation, promoting apoptosis and inhibiting cell migration of breast cancer cell MCF-7 [5], but its molecular mechanism still needs to be further explored. It is of great significance to study the drug target and mechanism of mangiferin for the development of potential anti breast cancer effect of mangiferin. Through the study of Caryophyllin inducing
ROS dependent apoptosis and inhibiting the growth of Hep3B cells, an chin Cheng [6] found that Caryophyllin is a potential apoptosis inducer, which can activate death receptor and mitochondrial apoptosis pathway, and has a good therapeutic application in p53 independent cancer cell apoptosis. It was found that Caryophyllin could inhibit the proliferation and clone formation of human oral squamous cell carcinoma cell line cal27, and increase the level of glycolysis. CNE2 cells were treated with the extract of total oxaanthrone from mangosteen peel, and the growth inhibition of CNE2 cells was determined by MTT method $[7,8]$. The results showed that the extract of total oxaanthrone from mangosteen peel could inhibit the proliferation of CNE2 cells and induce the apoptosis of CNE2 cells, and had a dose-dependent and timedependent relationship.

Table2. the antitumor active components in the pericarp of mangosteen

\begin{tabular}{|c|c|c|c|c|}
\hline $\begin{array}{c}\text { Active } \\
\text { ingredient }\end{array}$ & $\begin{array}{c}\text { Molecular } \\
\text { formula }\end{array}$ & Chemical structure formula & $\begin{array}{c}\text { Physical and chemical } \\
\text { properties }\end{array}$ & Mechanism of action \\
\hline Mangiferin & $\mathrm{C}_{25} \mathrm{H}_{30} \mathrm{O}_{7}$ & & $\begin{array}{l}\text { Pale yellow acicular } \\
\text { crystal. }\end{array}$ & $\begin{array}{l}\text { Inhibit the proliferation of MCF-7 } \\
\text { (human breast cancer cell) by } \\
\text { promoting mitochondrial dependent } \\
\text { apoptosis pathway, and effectively } \\
\text { reduce the migration of MCF-7 cells. }\end{array}$ \\
\hline
\end{tabular}




xanthone
$\begin{gathered}\gamma- \\ \text { mangostin } \\ \text { mangostin }\end{gathered} \mathrm{C}_{24} \mathrm{H}_{26} \mathrm{O}_{6}$

\subsection{Anti ultraviolet radiation effect}

For n-butanol extract from mangosteen, $\alpha$-mangostin, rutin, and nano $\mathrm{TiO} 2$, the absorption rate in different wavelengths of ultraviolet region was determined. The results showed that the extract of n-butanol and the effect of mangosteen on the UV radiation resistance were studied, $\alpha$-mangostin has good anti-ultraviolet and sun protection effect, especially $\alpha$-mangostin has a very strong spectral sunscreen effect [9]. When the concentration of the test solution was $0.05 \mathrm{mg} / \mathrm{ml}$, the results showed that the absorptivity of $\alpha$-mangostin was more than $85 \%$ in the three UV regions, and more than $90 \%$ in UVB and UVA regions. When the concentration of $\alpha$-mangostin was more than or equal to $0.01 \mathrm{mg} / \mathrm{ml}$, the average absorptivity was more than $90 \%$, while the absorptivity in UVB and UVA regions was close to $100 \%$.

\subsection{Antioxidant activity}

Polyphenol extract from mangosteen pericarp has good antioxidant activity in vitro, and the antioxidant activity of polyphenols in aqueous phase is stronger than that in organic phase[10]. It was found that the scavenging activity of crude Proanthocyanidins from mangosteen pericarp was stronger than that of VC on DPPH and $\mathrm{O} 2$ radicals, and the scavenging ability of $\cdot \mathrm{OH}$ was worse than that of VC[11]. Response surface methodology (RSM) was used to optimize the ultrasonic assisted extraction process of Polysaccharides from mangosteen pericarp and its antioxidant activity in vitro. It was found that mangosteen pericarp polysaccharides had good scavenging effect on oxygen-containing and nitrogencontaining free radicals, and the performance increased with the increase of polysaccharide concentration.

The ethanol extract of mangosteen peel has obvious antioxidant effect on the pupa oil rich in polyunsaturated fatty acids, and when the ethanol extract is combined with vitamin $\mathrm{C}$ and vitamin $\mathrm{E}$, its antioxidant effect is significantly enhanced, showing a good synergistic antioxidant effect. Study on the inhibition of human LDL oxidation of $\alpha$-mangostin from the isolation and purification of mangosteen was studied by ETA Williams[13,14]. It can be used as a free radical scavenger to protect LDL from oxidative damage in vitro.

\subsection{Neuroprotective effect}

Water extract of mangosteen pericarp (MPW) can enhance memory through antioxidant neuroprotection and anti apoptosis. Oh Yeonsoo[15] found that (MPW) could inhibit a $\beta$ It can also reduce lipid peroxidation, scavenge 1,1-diphenyl-2-picrylhydrazine free radical and ensure its antioxidant activity. Tang Zhuoya [16] isolated 22 flavonoids from the extract of mangosteen peel, and studied their neuroprotective effects on glutamate induced cell death in mouse hippocampal nerve cell line HT22. From the preliminary cytotoxicity test results, it was found that most of the compounds in $30 \mu$ HT22 cells showed no obvious cytotoxicity at the concentration of $10 \mathrm{~mol} / \mathrm{L} \mu$ The results showed that 11 compounds could protect HT22 cells from glutamate induced death. Even if these active compounds were added in $1 \mu$ Compounds 6 and 8 could still show neuroprotective effect when evaluated at the lowest concentration.

\subsection{Improving cardiovascular disease}

Hydroxycitric acid (HCA) mainly exists in Garcinia plants. Studies have shown that HCA can enhance the activities of lipoprotein lipase and liver lipase, accelerate lipolysis, and reduce the synthesis of triglycerides [17]. The mechanism of action is that HCA inhibits the cleavage of citric acid to oxaloacetic acid and acetyl coenzyme A in vitro by inhibiting the activity of citrate lyase. Acetyl coenzyme A exists as an intermediate in the process of fat 
conversion and plays a key role in the process of energy storage as fat. Yu Quan[18] found that HCA can be used as an effective component of diet supplement for weight loss, with the functions of weight loss, enhancing aerobic exercise endurance, removing stones, lowering blood lipid and improving cardiovascular and cerebrovascular. Research found $\alpha$-mangostin can also activate receptors by inhibiting peritoneal proliferators $\gamma$ (PPARy expression, limited adipocyte differentiation, increased glucose uptake and inhibited lipid accumulation by regulating glucose transporter 4 (GLUT4) and leptin.

\subsection{Protection of intestinal diseases}

The results showed that proanthocyanidins had strong antioxidant activity. Liu Chu[19,20] studied the chemical changes of proanthocyanidins in the digested mangosteen peel and their effects on intestinal microflora, and found that the digested mangosteen peel proanthocyanidins can be degraded in the large intestine and colon, so as to improve the intestinal microbial metabolism and the abundance of main microflora, and play a role in protecting intestinal diseases.

\section{Extraction of Flavonoids from mangosteen peel}

The extraction methods of Flavonoids from mangosteen pericarp include supercritical fluid extraction, water extraction, organic solvent extraction and vegetable oil assisted extraction.

\subsection{Water extraction method}

The solvent of water extraction method is water, which is suitable for industrial production because of its low cost, non-toxic effect on environment and human, and simple equipment. However, the extraction rate is low, there are many impurities in the extract, and the subsequent separation steps are cumbersome. The dried pericarp of mangosteen was $7.9 \mathrm{~kg}$, refluxed with 7.91 distilled water at $100{ }^{\circ} \mathrm{C}$ for 2 hours, and $298.7 \mathrm{~g}$ crude extract of MPW was obtained [15].

\subsection{Organic solvent extraction}

The organic solvent extraction method uses ethanol, ether, chloroform, acetone, petroleum ether and so on, and its extraction efficiency is greatly improved compared with the water extraction method. However, the amount of solvent used is large and the extraction times are many. When using, it is necessary to strengthen ventilation, reduce the escape and evaporation of organic solvent, and pay attention to personal protection. When $60 \%$ ethanol solution was used to extract mangostanin, mangostanol, 8desoxygartanin, gartanin and mangostanol from mangosteen pericarp by reflux extraction for three times $\alpha$ - The separation rates of mangostin were $1.12,1.38,1.22$, 0.85 and $2.87 \mathrm{mg} / \mathrm{g}$; The purity was $94.35 \%, 94.28 \%$, $95.45 \%, 98.68 \%$ and $97.54 \%$, respectively[22].

\subsection{Supercritical fluid extraction}

The supercritical fluid extraction method uses $\mathrm{CO} 2$, ethylene, ethane, propylene, ammonia, water and so on. The entrainer can be used to improve the extraction efficiency. Its advantages are high extraction efficiency, environmental protection and no pollution. When extracting and separating natural substances, it has selective [23-25] in high pressure, closed and inert environment, and Gartanin in extracting mangosteen pericarp. $\alpha$ - When the extraction temperature is $60^{\circ} \mathrm{C}$, the outlet valve temperature is $90^{\circ} \mathrm{C}$, the pressure is 350 bar, the extraction time is $0.5 \mathrm{~h}$, the extraction is twice, the entrainer is anhydrous ethanol, and the purity of the extract is $90 \%$ and $95 \%$, the total phenol content can reach 365 mg GAE/100g.

\subsection{Auxiliary extraction of vegetable oil}

The natural coconut oil is used as the extraction solvent in the vegetable oil assisted extraction method. When the vegetable oil is used as the extraction solvent, it can stabilize the solute. The process is simple and easy to operate, reduce the extraction cost and reduce the pollution. However, the vegetable oil is a mixed solvent, which is not easy to volatilize and separate. At the same time, the selectivity is not high enough, and it is difficult to extract the substances with strong polar substances and large molecular weight, It is usually necessary to introduce the entrainer containing polar group [26]. In the extraction experiment of polyphenols from mangosteen pericarp, based on the single factor experiment of natural coconut oil and ultrasonic assisted extraction, it was found that when the ratio of sample to solvent was $1: 6.6 \mathrm{~g} / \mathrm{ml}$, the amplitude was $55 \mu \mathrm{m}$. The optimum extraction time was 7 $\mathrm{min}$, and the total phenol content was $365 \mathrm{mg} \mathrm{GAE} / 100 \mathrm{~g}$.

\section{Conclusion}

In the field of food and health products, the pigment content in the pericarp of mangosteen is rich, and it has stability and antibacterial activity, which can be used as the extraction material of natural edible pigment. Flavonoids have the activities of scavenging free radicals and toxins, antibacterial, anti-inflammatory and anti allergic, which can be used to develop new green food preservatives. Using the antioxidant activity of mangosteen peel extract, it can also be added to dairy products to enhance the antioxidant properties of yogurt beverage[27,28]. In the field of medicine, mangosteen extract can effectively eliminate free radicals and inhibit the production of pro-inflammatory cytokines. In the study it is found the effect of $\alpha$-mangostin of anti-twisting element on metabolic diseases, which can reduce the blood glucose of alloxan diabetic mice, improve the abnormal glucose tolerance, reduce the serum total cholesterol content of obese mice induced by high-fat diet, and regulate the abnormal lipid metabolism of obese mice, It was found that mangosteen extract could regulate MAPK/ERK1/2 signaling pathway and apoptosis related proteins in tumor cells by inducing oxidative damage, and 
then induce apoptosis, thereby inhibiting the proliferation of tumor cells[29, 30]. The extract of mangosteen has a significant inhibitory effect on the proliferation of cervical cancer cells. Among the extraction methods of active components from mangosteen pericarp, supercritical fluid extraction and vegetable oil assisted extraction have the characteristics of green nature, environmental protection and energy saving, and have broad market prospects in the development and utilization of mangosteen pericarp

\section{Acknowledgments}

This work was supported by the (Key) Project of Department of Education of Guangdong Province (No2018ktscx270); Construction and management of laboratory (training room) in Guangzhou College of Technology and Business in 2019(Research on the construction of safety evaluation system of food testing laboratory for application oriented Undergraduate).

\section{Reference}

1. Ganlong L, GNU, (2014)

2. Wenshu P,Yijian C,Wenwu Z,Xue S, Yong X, Food R\& D, 12 (2011)

3. uochun Y, Jing Z, Ying Z, Jianhui, Y.Chao, F.Gang, CJTA, 02 (2016)

4. C. Yen Shuo,W.Jia Lin, Y.Chi Tai, Y.Vijesh Kumar, Aging, 8 (2020)

5. Kaiyue H, Minyan L, Chen T, Changrui L, Yue Z, J.Biol., 06 ( 2020)

6. C.An Chin,T.Mei Ling,L.Chi Mei,L.Ming Fen,N.Kalyanam, F\& function, 3 (2010)

7. Hua L. E3S Web of Conferences, 145(2020)

8. Yanyan L, Yingwen H, Danyang H,Lanlan W,Binyou L, Prescriber. 1 (2016)

9. Chengzhong Z, Jilin AU, (2011)

10. Haiguang C, Zhaoxia L, Limei Y, STFI,(2011),32(09)

11. Qing Y. Jimei University, (2013)

12. Shan L, Jian L, Bin F, Xiaofeng L, Liqing X,Food R.D, $10(2020)$

13. Yunfei L, Liqun L, Kedi Y, STFI, 06 (2010)

14. P Williams, M Ongsakul, J Proudfoot, K Croft, L Beilin, Taylor \& Francis, 2 (2009)

15. O.Yeonsoo, D.Ha Thi Thu, K.Sunyoung, K.YoungMi, Antioxidants, 1 (2020)

16. Zhuoya T, Yuehua P, Junsheng Z, Sheng Y, Guihua T, Acta Sci. 06 (2020)

17. P Mengling, L Longlong, $\mathrm{Y}$.Lei, G Chongyang, M Haitian, Anim. Sci. J, 1 (2018)

18. Quan Y, Yihong H, CL, (2020),40(3)

19. Chu L, Zhejiang Gongshang University, (2020)

20. Yuan F, Tu S, Ping X, Songtao Y, Wen F, IJO, 7 (2015)

21. N.Tataph,W.Chatu,K.Jarukamjorn,J. Ethno, 265
(2021)

22. Junqi R, Changchun Normal University, (2015)

23. Kairong Z, Tiemin X, AS\& TE, 06 (2020)

24. Wenxin R, Tiantian L, Yu W, MF,22 (2019)

25. Jing Y, Changchun, NU,(2012)

26. C Sungpud, W Panpipat, A SaeYoon,M Chaijan, J. Food Sci.Technol, (2020)

27. Xiuying S, Ali W Yimin Z, Shanquan F, Youli Z. MFST, 03 (2006)

28. Shuang L, Ying L, Dan W, Wen Z, Chao L, Food industry, 12 (2012)

29. J M W Wibawanti,Rinawidiastuti,H D Arifin,Zulfanita. EES, 1 (2018)

30. Kaiqiang L,Ke H,Yili C,Bingyu C,Shanshan J,Wei Z,ZJITCWM, 02 (2020) 